Check for updates

Cite this: RSC Adv., 2017, 7, 43197

Received 21st July 2017

Accepted 30th August 2017

DOI: $10.1039 / \mathrm{c} 7 \mathrm{ra} 08080 \mathrm{~h}$

rsc.li/rsc-advances

\section{Theoretical investigation on proton transfer mechanism of extradiol dioxygenase $\uparrow$}

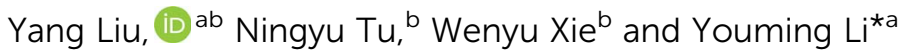

A QM/MM method ONIOM (B3LYP: Amber) was employed to discuss the catalytic mechanism of non-heme iron extradiol dioxygenases (HPCD). Previous research suggested that protonation of alkylperoxo intermediate was achieved by transferring the proton from monoanionic catechol substrate to superoxide anion via the histidine residue near the active site. Herein, our results demonstrated that the proton was transferred from the monoanionic catechol substrate to the superoxide anion directly. The catalytic mechanism could be performed via two parallel pathways, named pathway A and B. Both of them consisted of a proton-transfer process and distal oxygen attack procedure but occurred in a different sequence. Our key mechanistic discovery for catalytic reactions revealed a two-state reactivity (TSR) scenario, in which quintet state crossed over the septet state. Pathway A was more kinetically and thermodynamically favorable.
\end{abstract}

\section{Introduction}

The mechanism for catechol ring-cleavage catalyzed by nonheme iron (or manganese) extradiol dioxygenases has attracted much attention for many years due to its significance for degradation of aromatic compounds. ${ }^{1-5}$ Extradiol dioxygenases include 2,3-dihydroxybiphenyl 1,2-dioxygenase (DHBD), catechol 2,3-dioxygenase (2,3-CTD), homoprotocatechuate 2,3dioxygenase (HPCD), protocatechuate 4,5-dioxygenase (4,5PCD), and homogentisate 1,2-dioxygenase (HGO), which all contain a 2-His-1-carboxylate facial triad. ${ }^{6,7}$ Prior studies have mostly focused on two extradiol dioxygenases: HPCD ${ }^{8-12}$ and DHBD. ${ }^{13-15}$ Remarkably, three key intermediates (superoxo, alkylperoxo and bound product) of HPCD with a slow substrate 4-nitrocatechol (4NC) was captured by experimental methods, ${ }^{\mathbf{1 6}}$ the whole catalytic mechanism became more and more clear..$^{13,17,18}$ Several consensus reaction steps are shown in Scheme 1. Firstly, $\mathrm{Fe}-\mathrm{O}_{2}$ adduct generates a key intermediate (alkylperoxo species) after a series of catalytic reactions. An O-O bond cleavage and a Criegee rearrangement process follow subsequently to yield an oxepine intermediate. Finally, attack on the substrate by an $\mathrm{OH}$ group leads to $\mathrm{C}-\mathrm{O}$ bond breaking and forms the final product.

On the one hand, experimental studies have proved that the protonation of alkylperoxo is very important for $\mathrm{O}-\mathrm{O}$ bond

${ }^{a}$ State Key Laboratory of Pulp and Paper Engineering, South China University of Technology, Guangzhou 510640, P. R. China.E-mail: ymli3@scut.edu.cn

${ }^{b}$ Faculty of Environmental \& Biological Engineering, Guangdong University of Petrochemical Technology, Maoming 525000, P. R. China

$\dagger$ Electronic supplementary information (ESI) available: Spin population distribution, optimized structures in triplet and septet states, and Cartesian coordinates of optimized structures. See DOI: 10.1039/c7ra08080h cleavage. ${ }^{19,20}$ It is generally accepted that the proton caused the protonation of alkylperoxo comes from the monoanionic catechol substrate, which has been confirmed by the available UV resonance Raman spectroscopic and electronic absorption spectroscopic data ${ }^{\mathbf{1 3 2 1 - 2 3}}$ and the asymmetric binding X-ray crystal structure of the enzyme-substrate complex. ${ }^{24,25}$ However, the protonation mechanism of alkylperoxo is still under debate, because no intermediate is captured by experimental methods before the formation of $\mathrm{Fe}(\mathrm{II})$-alkyl(hydro) peroxo species in wild-type (WT) enzyme reaction. On the other hand, research results have showed that the histidine residue (His200 of HPCD) near the active site has a marked influence on the activity of catalytic reaction. ${ }^{25-27}$ Considering the above two aspects, several researchers suggested that His200 could participate in the proton-transfer process and speculated that the monoanionic substrate gave a proton to the His200, which was then passed to superoxide anion. ${ }^{17,19}$ In order to explain the above mechanism in more detail, attempts based on DFT calculation have been carried out. ${ }^{28-31}$ Christian and coworkers ${ }^{28}$ suggested that the proton-transfer and oxygen addition process consisted of several steps (Scheme 2): (a) His200 abstracted a proton from the hydroxyl group of the catecholic substrate. (b) Formed H-bonding between distal oxygen atom

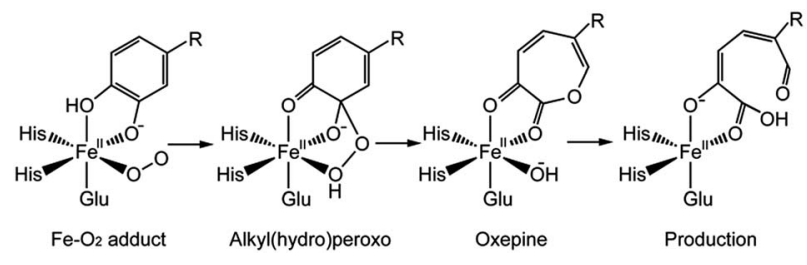

Scheme 1 Proposed catalytic mechanism of extradiol dioxygenase. 


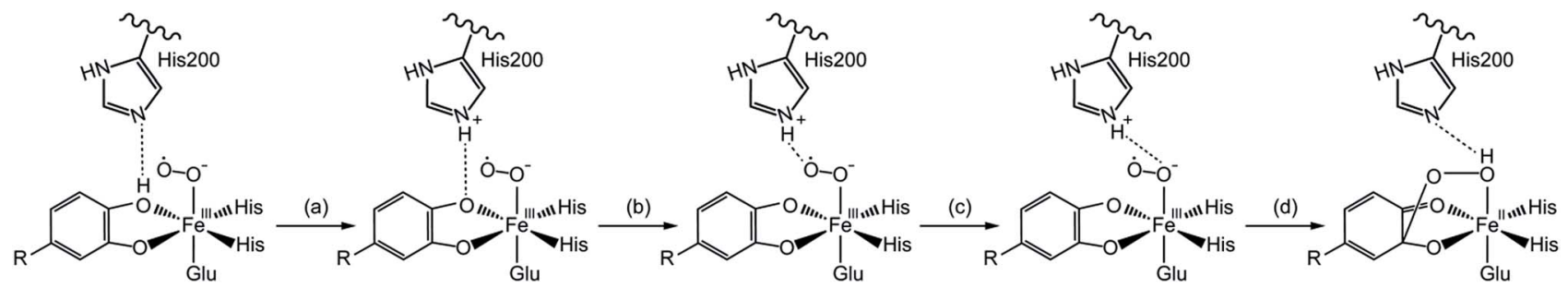

Scheme 2 The proton transfers from the substrate to hydrogen-bonding for the $\mathrm{Fe}-\mathrm{O}_{2}$ adduct. ${ }^{28}$

$\left(\mathrm{O}_{\mathrm{d}}\right)$ of superoxide anion and the proton of His200 by rotational transition state of protonated His200. (c) Formed H-bonding between proximal oxygen atom $\left(\mathrm{O}_{\mathrm{p}}\right)$ of dioxygen and His200 by reorientation of His200. (d) $\mathrm{O}_{\mathrm{d}}$ added on aromatic ring, meanwhile, and the proton of His200 transferred to $\mathrm{O}_{\mathrm{p}}$ via the same transition state.

In the light of the results for recent mutant experiment of HPCD, ${ }^{32}$ the researchers speculated two different catalytic mechanisms of proton-transfer process for WT enzyme and mutant ones respectively. For WT enzyme, the proton passed from monoanionic substrate to superoxo anion via His200 as in the reaction pathway showed in Scheme 2. For mutant enzyme, as His200 was replaced by Asn200 or Gln200 which had no ability of accepting or providing proton, the proton-transfer process would perform without the help of His200 variants. However, another possibility, that the His200 or His200 variants didn't play a role in carrying proton, has been ignored. The proton-transfer process was carried out between the monoanionic substrates and superoxide anion directly, and the weak interaction between residue 200 and the proton still has an effect on the whole system. It seemed a good interpretation on why the proton-transfer procedure still occurred when the His200 was replaced by Asn200 or Gln200.

To confirm our ideas on the catalytic mechanism of HPCD, quantum mechanics/molecular mechanics (QM/MM) calculations were implemented. We focused on the mechanism of proton transfer between the monoanionic substrate and dioxygen, and revealed the most favorable pathway for the formation of Fe-alkylperoxo species in WT HPCD by computational methods.

\section{Computational methods and models}

\subsection{System build and classical MM calculations}

The initial structure of HPCD (EC 1.13.11.15, and PDB code $4 \mathrm{GHG}$ ) was obtained from the Protein Data Bank. The whole protein was used to study the oxygenation reaction. The water molecule above the Fe atom in the active site was replaced by one dioxygen molecule. All classical molecular mechanics (MM) calculations have been performed with AMBER ff14SB force field and TIP3P water model. ${ }^{33}$ The protonated states of the protein residues were predicted using the $\mathrm{H}++$ website. ${ }^{34,35}$ The prepared structure was surrounded by a cubic box of TIP3P water molecules having a minimum distance of $8 \AA$ between the protein and the end of the box, and neutralized by adding $\mathrm{Na}^{+}$ counter ions with the AMBER Leap module. ${ }^{36,37}$ Ligand was treated by gaff AMBER force field, charges and atom types for all amino acid residues and $\mathrm{Fe}$ atom were obtained from the AMBER library.

Three steps of system minimizations were performed before molecular dynamics simulation. Firstly, position constraints were enforced for the whole protein and ligand with the $500 \mathrm{kcal} \mathrm{mol}^{-1} \AA^{-2}$ harmonic potentials, the water molecules and counterions were first optimized. Secondly, a further minimization using a force constant of $10 \mathrm{kcal} \mathrm{mol}^{-1} \AA^{-2}$ on the atoms in His200, His155, His214, Glu267, Arg243, Tyr257, Trp192, native substrate (homoprotocatechuate, HPCA), Fe atom, and dioxygen. Thirdly, the entire system was minimized without restraint. A cutoff radius of $10 \AA$ was used for nonbonding interactions, and long-range electrostatic interactions were treated by the Particle Mesh Ewald (PME) method. ${ }^{38}$ A $50 \mathrm{ps}$ simulation of the heating from $0 \mathrm{~K}$ to $300 \mathrm{~K}$ with force constants was taken place, followed by 200 ps simulation with constant pressure. Finally, a 14 ns molecular dynamics simulation in the NVT ( $300 \mathrm{~K}, 1 \mathrm{~atm})$ ensemble was carried out. In order to obtain the initial structure for QM/MM work, a $50 \mathrm{ps}$ cooling simulation was applied from $300 \mathrm{~K}$ to $0 \mathrm{~K}$. Counterions and water molecules $5 \AA$ away from the protein were removed. Thus, the final system containing 7775 atoms was the initial model for the next ONIOM study. An additional 6 ns MD simulation was performed to test the stability of the whole system. The 3D structure of HPCD reached a stable state after 14 ns where the RMSD of the protein backbone atoms converged to $2.2 \AA$ (Fig. S1†).

\section{$2.2 \mathrm{QM} / \mathrm{MM}$ models and methods}

In order to present the $\mathrm{QM} / \mathrm{MM}$ calculations, ONIOM method implemented in the Gaussian 09 D.01 was used..$^{39}$ The ONIOM method $^{40}$ works by approximating the energy of the real system as a combination of the energies computed by less computationally expensive means. Specifically, the energy was computed as the energy of the model with corrections for the size difference between model and real and for the method accuracy difference between the molecular mechanics and the quantum mechanics method used for model (denoted MM and QM in the following equation):

$$
\begin{gathered}
E_{\mathrm{QM}, \text { real }} \approx \\
+E_{\mathrm{MM}, \text { model }}+\left(E_{\mathrm{MM}, \text { real }}-E_{\mathrm{MM}, \text { model }}\right) \\
+\left(E_{\mathrm{QM}, \text { model }}-E_{\mathrm{MM}, \text { model }}\right)
\end{gathered}
$$




$$
E_{\mathrm{ONIOM}, \mathrm{QM}: \mathrm{MM}}=E_{\mathrm{MM}, \text { real }}+E_{\mathrm{QM}, \text { model }}-E_{\mathrm{MM} \text {,model }}
$$

A two-layer ONIOM method was used for the QM/MM study of the catalytic mechanism of HPCD. The geometry structures of QM parts were optimized by the B3LYP density functional theory method and MM parts were treated by AMBER ff14SB force field at the mechanical embedding level. Fe atom, imidazole rings of the His155, His214 and His200, $\mathrm{CH}_{2} \mathrm{CO}_{2}{ }^{-}$part of the Glu267, guanidine of the Arg243, HPCA and dioxygen were all selected as QM region. A valence double-zeta polarized basis set 6-31G(d) was used. The charge value of QM part was zero, and the total net charge of the whole system was -16 .

The atomic charges of the QM region were treated by the RESP $^{41}$ (restrained electrostatic potential) program at the B3LYP/6-31G(d) level of theory. The change of the QM region charge distribution during the reaction could reduce the accuracy of the ONIOM energies. Therefore, geometry optimizations of all stationary points were carried out by several steps. First of all, intermediates and transition structures were optimized by ONIOM calculations at mechanical embedding level with an initial set of charges. Secondly, an improved set of atomic charges of QM region were obtained by using the RESP procedure, after that, a further optimization was carried out with the improved charges. Finally, the above step could be repeated several times until the ONIOM energy difference between the last two rounds was very slight. The ONIOM energy of the optimized structure was computed at the mechanical embed$\operatorname{ding}(\mathrm{ME})$ levels with a larger triple-zeta basis sets 6-311+G(d,p). Meanwhile, the ONIOM energy was combined with a thermal correction to the Gibbs free energy computed at the ONIOM-ME (B3LYP/6-31G(d):Amber) level.

\section{Computational results and discussion}

Previous evidences ${ }^{\mathbf{4 2 , 4 3}}$ proved that the Fe ion was formed as quintet $\mathrm{Fe}(\mathrm{II})$ in the crystal, since the combination of quintet $\mathrm{Fe}(\mathrm{II})$ with triplet $\mathrm{O}_{2}$ led to three possibilities of spin combinations, the high-spin (septet), intermediate spin (quintet), and low spin (triplet). The previous DFT model studies ${ }^{28-30}$ suggested that the quintet spin state or septet state might be the ground state. Meanwhile, the experimental result indicated a quintet ground state by characterizing a high-spin $S_{1}=5 / 2$ $\mathrm{Fe}(\mathrm{III})$ antiferromagnetically (AF) coupled to $S_{2}=1 / 2$ superoxo radical in $\mathrm{H} 200 \mathrm{~N}$ mutant experiment of HPCD with $4 \mathrm{NC}$ substrate. ${ }^{27}$ However, for one thing, the electronic structure of Fe-superoxo species for mutant enzyme may be different from the WT one. For another, the catalytic mechanism suggested in this study is different from the former ones. Hence, it is necessary to discuss all possibilities for triplet state, quintet state and septet state.

\subsection{The character of reactive species $\left(\mathrm{Fe}-\mathrm{O}_{2}\right.$ adduct $)$}

After further analysis, different orientation of $\mathrm{O}_{\mathrm{d}}$ form different reactive species. There are two possibilities orientations, the $\mathrm{O}_{\mathrm{p}}-\mathrm{O}_{\mathrm{d}}$ bond axes near the plane of $\mathrm{Fe}-\mathrm{O}_{\mathrm{p}}-\mathrm{O} 2$ for $\mathbf{1}$, and the $\mathrm{O}_{\mathrm{p}}-$ $\mathrm{O}_{\mathrm{d}}$ bond axes near the plane of $\mathrm{Fe}-\mathrm{O}_{\mathrm{p}}-\mathrm{O} 1$ for $\mathbf{1}^{\prime}$, as shown as in Scheme 4. A DFT calculation is carried out to obtain optimized structures (shown in Fig. $\mathrm{S} 2 \dagger^{\dagger}$ ) and relative energies for $\mathbf{1}$ and $\mathbf{1}^{\prime}$

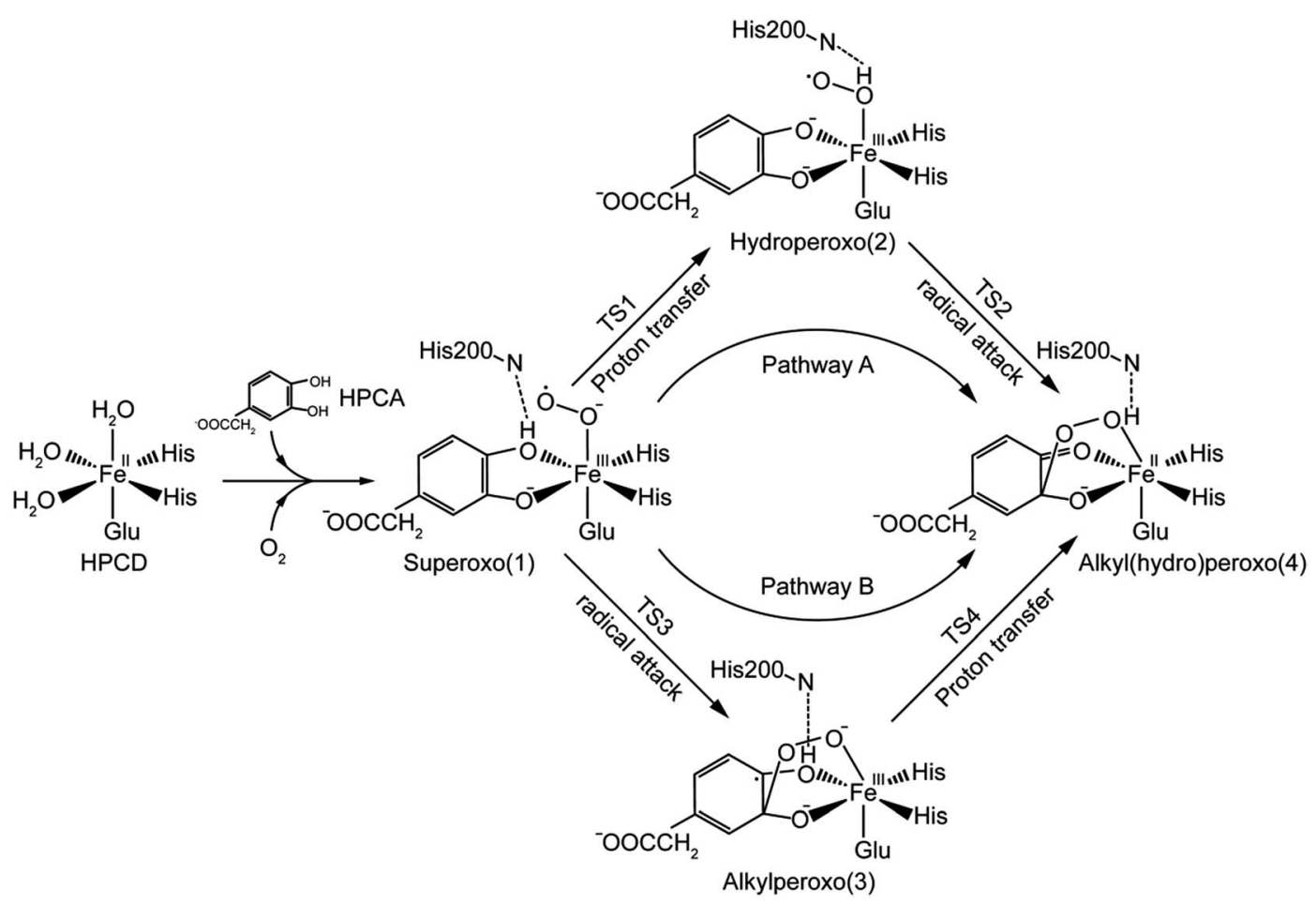

Scheme 3 The catalytic mechanism for the formation of alkyl(hydro)peroxo species. 

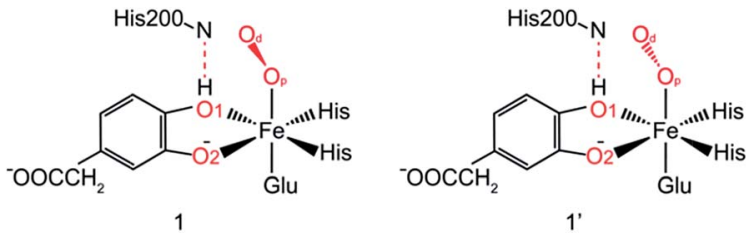

Scheme 4 Different $\mathrm{O}_{d}$ orientation of $\mathrm{Fe}-\mathrm{O}_{2}$ adducts for WT HPCD.

in quintet state. The result shows that the difference of relative energy between ${ }^{5} \mathbf{1}$ and ${ }^{5} \mathbf{1}^{\prime}$ is very slight (less than $0.5 \mathrm{kcal} \mathrm{mol}^{-1}$ ). Because $\mathrm{O}_{\mathrm{d}}$ is nearly located between the proton and $\mathrm{O}_{\mathrm{p}}$ in ${ }^{5} \mathbf{1}^{\prime}$, the proton is very hard to move to $\mathrm{O}_{\mathrm{p}}$ directly around $\mathrm{O}_{\mathrm{d}}$. Hence, it seems that ${ }^{5} \mathbf{1}^{\prime}$ is not the reactive species of the catalytic mechanism we suggest. Differently, the orientation of $\mathrm{O}_{d}$ is vertical in plane of $\mathrm{H} 1-\mathrm{O} 1-\mathrm{O}_{\mathrm{p}}$ in ${ }^{5} \mathbf{1}$, the movement of proton in plane of $\mathrm{H} 1-\mathrm{O} 1-\mathrm{O}_{\mathrm{p}}$ is unblocked. Therefore, we put our attention on the $\mathbf{1}$ as reactive species in this study. The valence electron configurations of reactive species $\mathbf{1}$ for different spin states are shown in Fig. 1, which are unambiguously supported by the analysis of spin population distribution (Table $\mathrm{S} 1 \dagger$ ). For triplet state, three unpaired $\alpha$-spins are located on the iron, and one $\beta$-spin is situated on the dioxygen group (the unpaired electron occupies the out of $\mathrm{Fe}-\mathrm{O}_{\mathrm{p}}-\mathrm{O}_{\mathrm{d}}$ plane (op) $\pi^{*}$-orbital). For quintet state, five unpaired $\alpha$-spins are located

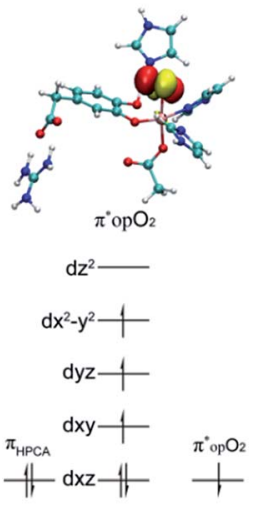

( $\left.{ }^{3} 1\right)$ triplet

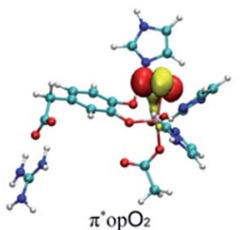

$\mathrm{dz}^{2}-1$

$d x^{2}-y^{2}-1$

dyz-1

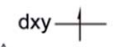

HPCA

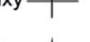

(51) quintet

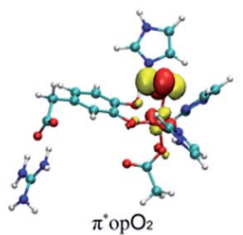

$\mathrm{dz}^{2}-1$

$d x^{2}-y^{2}-1$

dyz -1

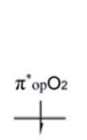

$\pi_{\mathrm{opO}_{2}} \quad \pi_{\mathrm{HPCA}} \mathrm{dxy}-1$

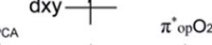

(71) septet
Fig. 1 The valence electron configurations of $\mathrm{Fe}-\mathrm{O}_{2}$ adducts for triplet state, quintet state and septet state.

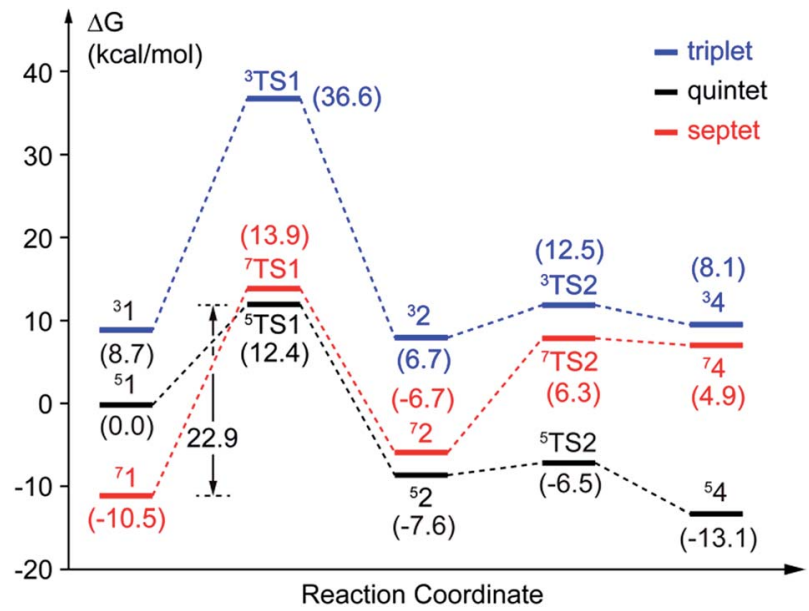

Fig. 3 Potential energy profiles of pathway A. The values with parentheses are relative free energies.

on the iron, and one $\beta$-spin is situated on the dioxygen group. For septet state, five unpaired $\alpha$-spins are located on the iron, and one $\alpha$-spin is situated on the dioxygen group. Obviously, the Fe ions are high spins in both quintet state and septet state. And the ${ }^{5} 1$ is presented as the character of an high spin $S_{1}=5 / 2$ Fe(III) AF coupled to $S_{2}=1 / 2$ superoxo radical which coincide with the experimental result of trapping and characterizing $\mathrm{Fe}(\mathrm{III})$-superoxo intermediate of HPCD. ${ }^{27}$ However, the septet Fe(III)-superoxide intermediate $\left({ }^{7} \mathbf{1}\right)$ involving a ferromagnetic coupling of Fe(III) with superoxo radical is the most stable form, lower in energy than that in the quintet state $\left({ }^{5} \mathbf{1}\right)$ and the triplet state $\left({ }^{3} \mathbf{1}\right)$ by 10.5 and $19.2 \mathrm{kcal} \mathrm{mol}^{-1}$, respectively (Fig. 3).

\subsection{Reaction mechanism}

In this study, two parallel pathways contain proton-transfer and oxo attack process are carried out to form alkyl(hydro)peroxo species. It is described as pathway $\mathrm{A}$ and $\mathrm{B}$ in Scheme 3. In pathway A, proton-transfer reaction takes place followed by $\mathrm{O}_{\mathrm{d}}$ attacks on the aromatic ring. In pathway $\mathrm{B}, \mathrm{O}_{\mathrm{d}}$ attacks and then proton transfers.

\subsubsection{Pathway A}

(a) Proton transfer. The above research illustrates that ${ }^{3} \mathbf{1},{ }^{5} \mathbf{1}$, and ${ }^{7} \mathbf{1}$ are all presented as superoxo radicals. By attacking of the superoxo radical anion, the proton transfers from 01 of HPCA
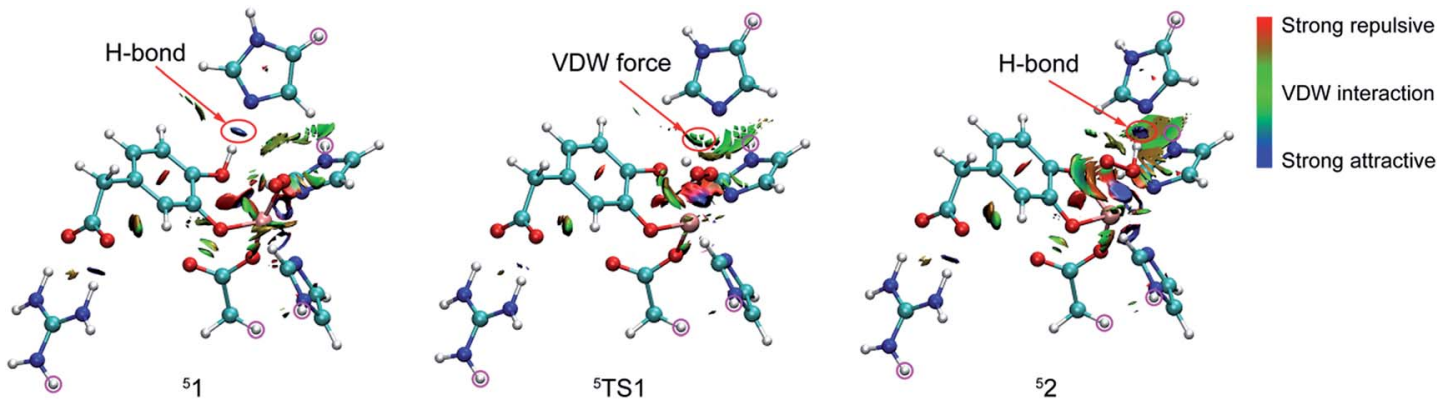

Fig. 2 RDG isosurface map for weak interaction of ${ }^{5} 1,{ }^{5} \mathrm{TS} 1$, and ${ }^{5} 2$. 
to $\mathrm{O}_{\mathrm{p}}$ of dioxygen. As shown in Fig. 3, the DFT-calculated barrier $\left(\Delta G_{\mathrm{Q}}^{*}\right)$ on quintet state potential energy surface (PES) from ${ }^{5} \mathbf{1}$ to ${ }^{5}$ TS1 is $12.4 \mathrm{kcal} \mathrm{mol}^{-1}$, which can be compared with that $\left(\Delta G_{\mathrm{T}}^{\ddagger}\right)$ of $27.9 \mathrm{kcal} \mathrm{mol}^{-1}$ on triplet state PES from ${ }^{3} \mathbf{1}$ to ${ }^{3} \mathbf{T S} 1$. This transition state stabilization of about $15.5 \mathrm{kcal} \mathrm{mol}^{-1}$ makes ${ }^{5}$ TS1 the energetically lowest transition state among all three proton-transfer transition states. This reaction picture is a typical TSR scenario. Starting from the septet ground state 1, a spin state transition to the quintet surface has to occur during this energetically most favorable proton-transfer step. The effective activation barrier $\Delta G_{\text {eff }}^{\ddagger}$ from ${ }^{7} \mathbf{1}$ to ${ }^{5}$ TS1 is $22.9 \mathrm{kcal} \mathrm{mol}^{-1}$. Additionally, triplet state is not likely to be involved during the proton-transfer process since it remains above the quintet and septet PESs. The key parameter of the intermediates and transition states are shown in Fig. S3. $\dagger$ According to the analysis of spin population distribution (Table $\mathrm{S} 1 \dagger$ ), the spin population distribution has little change in 1, TS1 and 2. It is indicated that there is little electron migration for this elementary reaction process. All optimized structures and key structural parameters of quintet state are shown in Fig. 4.

Reduced density gradient (RDG) and $\operatorname{sign}(\lambda 2) \rho$ function is employed to investigate the weak interaction between His200 and the proton. All calculations are carried out at B3LYP/6$31 \mathrm{G}(\mathrm{d})$ level for the QM region and the link atoms are signed

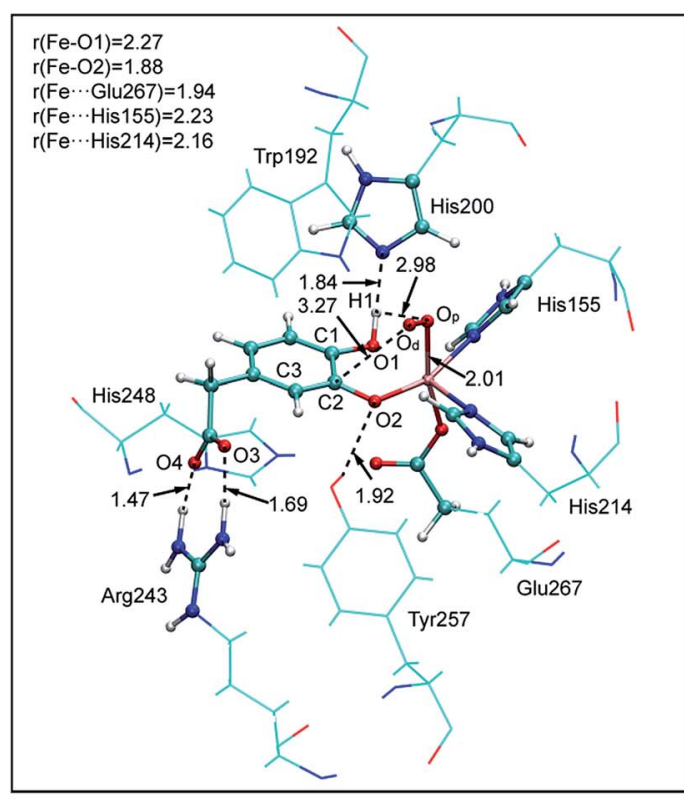

51

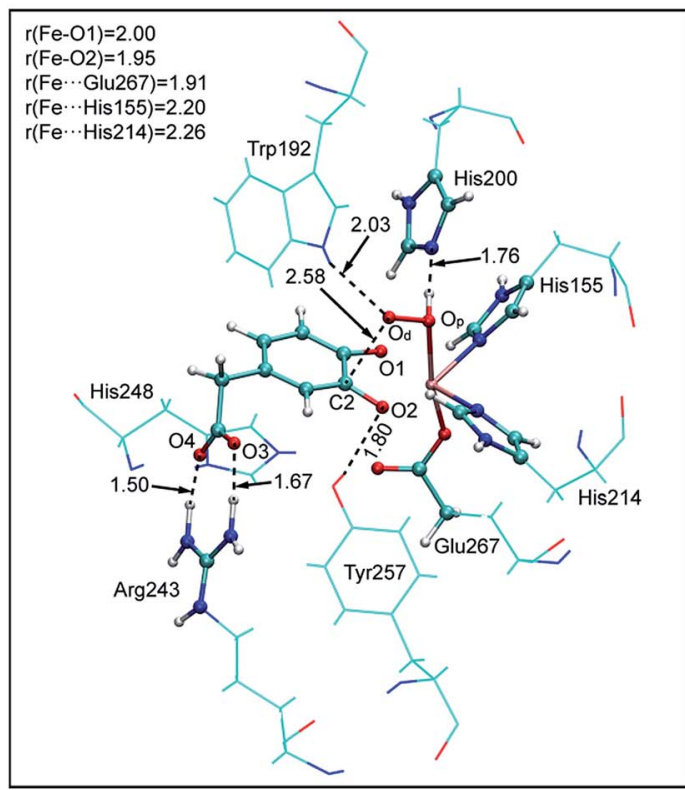

52

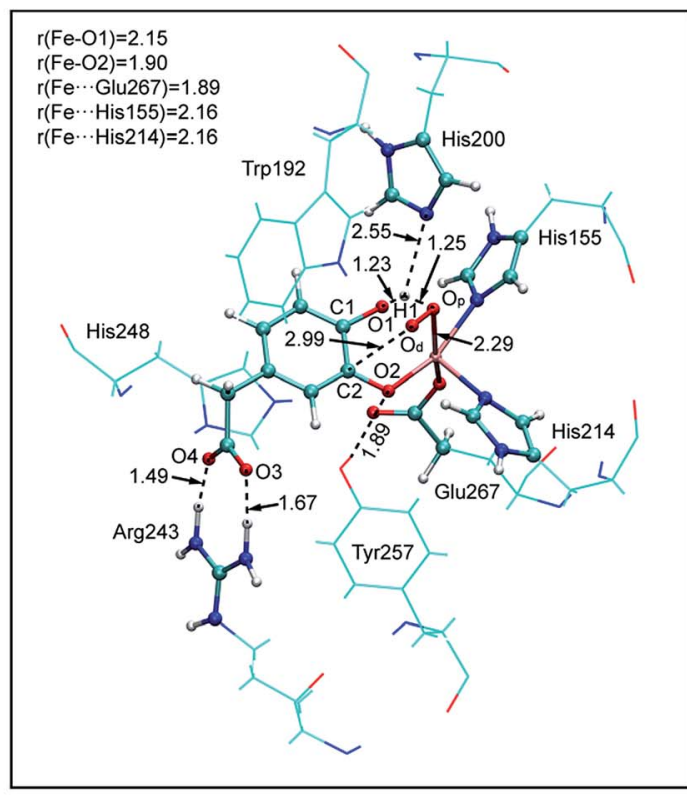

${ }^{5} \mathrm{TS} 1$

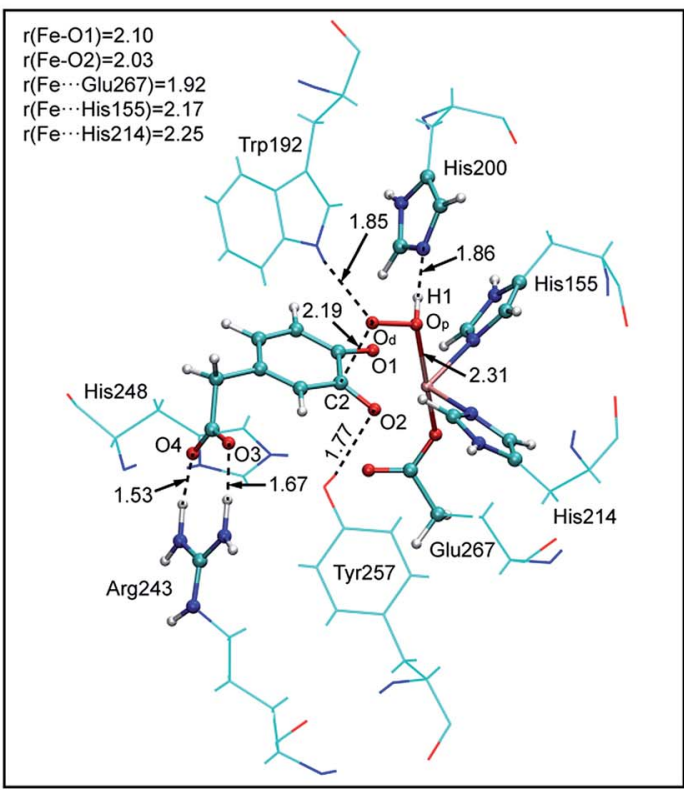

${ }^{5}$ TS2

Fig. 4 Calculated key structural parameters for intermediates and transition states of pathway A in quintet. Bond lengths ( $\AA$ ) are shown. 
by purple circle. As shown in Fig. 2, the blue, green, and red colors of RDG surfaces indicate the strong attractive, van der Waals interaction, and strong repulsive respectively. There is a strong $\mathrm{H}$-bond between His200 and the proton with $1.84 \AA$ in ${ }^{5}$ 1. And then length of the H-bond increases to $2.55 \AA$ in ${ }^{5}$ TS1. The color of the RDG surface is situated between blue and green, which indicates that the weak interaction is correspondingly weakened accompanied by an increase of system energy. Finally, the H-bond interaction enhances gradually in pace with the free energy of the system cut down, and the product $\left({ }^{5} 2\right)$ is formed. Obviously, the result indicates that the weak interaction makes contribution to the free energy barrier.
All analysis are performed and visualized by means of Multiwfn software. ${ }^{44}$

(b) Hydroperoxo attack. In this step, the distal oxygen of hydroperoxide radical attacks the $\mathrm{C} 2$ of aromatic ring to give the intermediate 4. The theoretical calculation shows that different electron-transfer mechanisms lead to different electron structures of alkyl(hydro)peroxo (shown in Fig. 7). For triplet state, one electron transfers from aromatic ring to superoxo accompanied with the gradually reducing distance of $\mathrm{C} 2$ and $\mathrm{O}_{\mathrm{d}}(2.84$ $\AA$ in ${ }^{3}$ 2, 2.01 $\AA$ in ${ }^{3}$ TS2, and $1.54 \AA$ in ${ }^{3} 4$, in Fig. S3†), resulting in the formation of $\mathrm{C} 2-\mathrm{O}_{\mathrm{d}}$ bond. But at the same time, another electron transfers from the electron-rich aromatic ring to the

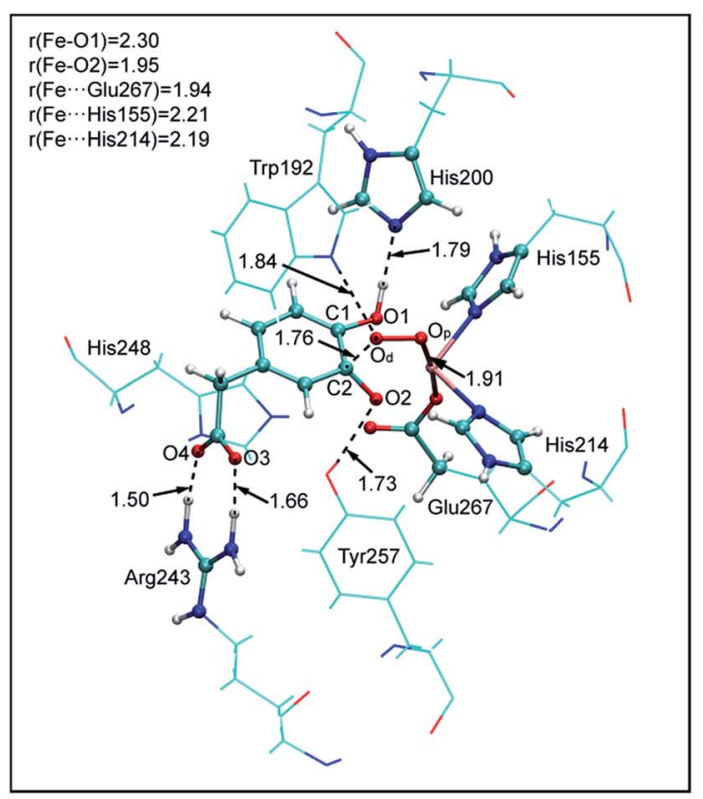

${ }^{5} \mathrm{TS} 3$

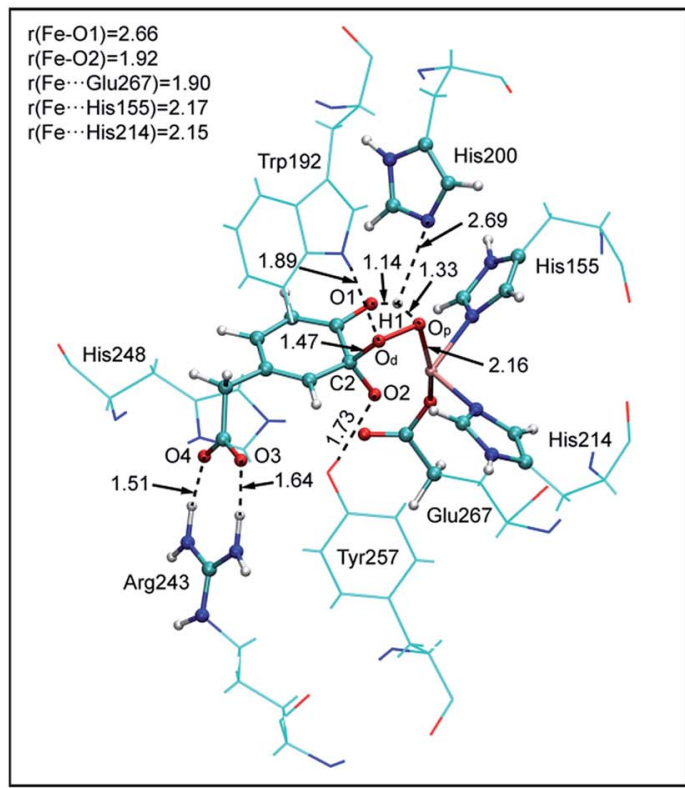

${ }^{5}$ TS4

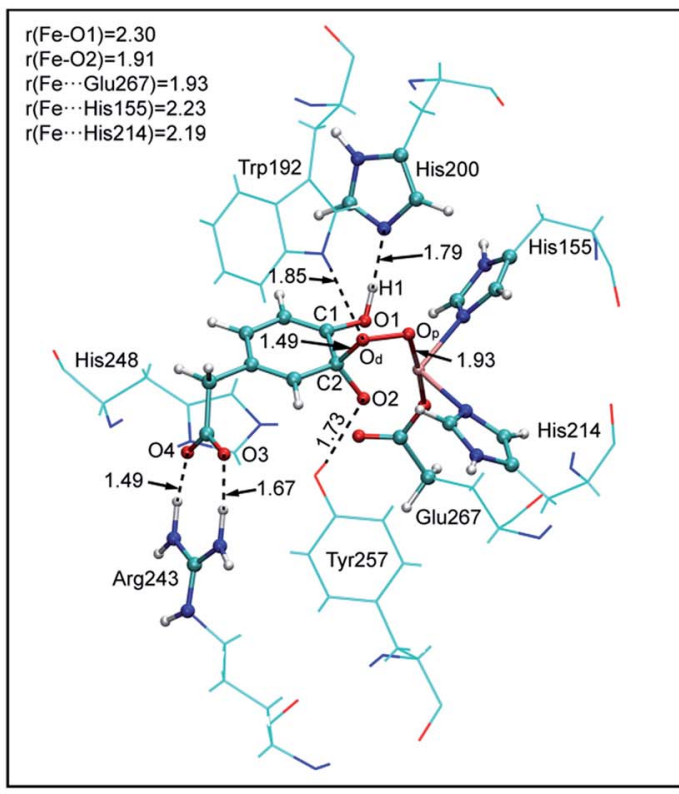

${ }^{5} 3$

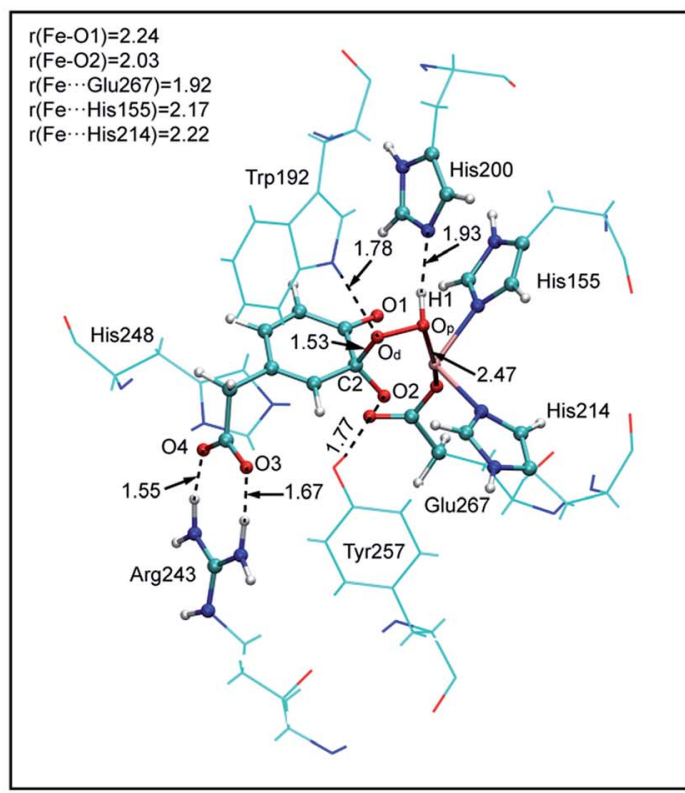

54

Fig. 5 Calculated key structural parameters for intermediates and transition states of pathway B in quintet. Bond lengths ( $\AA$ ) are shown. 
iron along with the increasing Fe-O1 bond length $\left(1.87 \AA\right.$ in ${ }^{3} 2$, $2.17 \AA$ in ${ }^{3} \mathbf{T S} 2$, and $2.31 \AA$ in ${ }^{3} \mathbf{4}$, in Fig. S3†). For quintet state, though the electron transfers in an analogous mechanism as in the triplet state, the bond lengths are different. When one electron transfers from aromatic ring to superoxo, the distance of $\mathrm{C} 2$ and $\mathrm{O}_{\mathrm{d}}$ reduces gradually from $2.58 \AA$ in ${ }^{5} 2,2.19 \AA$ in ${ }^{5} \mathrm{TS} 2$, to $1.53 \AA$ in ${ }^{5} \mathbf{4}$, as shown in Fig. 4, accompanied with the increasing Fe-O1 bond length $\left(2.00 \AA\right.$ in ${ }^{5} 2,2.10 \AA$ in ${ }^{5}$ TS2, and $2.24 \AA$ in $\left.{ }^{5} 4\right)$. For the septet state, one electron transfers from aromatic ring to superoxo accompanied with the gradually reducing distance of $\mathrm{C} 2$ and $\mathrm{O}_{\mathrm{d}}\left(2.86 \AA\right.$ in ${ }^{7} 2,1.84 \AA$ in ${ }^{7}$ TS2 , and $1.52 \AA$ in ${ }^{7} \mathbf{4}$, in Fig. $\mathrm{S} 4 \dagger$ ). The mechanism for the septet state differs from the former two. Since there is little electron transfer from the aromatic ring to the iron, the bond length of $\mathrm{Fe}-\mathrm{O} 1$ changes very slightly (1.99 $\AA$ in ${ }^{7} 2,2.00 \AA$ in ${ }^{7}$ TS2, and $2.00 \AA$ in $\left.{ }^{7} 4\right)$ and $\mathrm{Fe}(\mathrm{III})$-alkyl(hydro)peroxo is formed. This hydroperoxo attack process is thermodynamically endothermic in triplet and septet state but exothermic in quintet state. The quintet state is ground state for lowest energy profiles (shown in Fig. 3), with a very tiny barrier of about $1.1 \mathrm{kcal} \mathrm{mol}^{-1}$. It seems that this step happens very easily.

\subsubsection{Pathway B}

(a) Superoxo attack. This step involves a radical attack of superoxo radical at $\mathrm{C} 2$ position of the aromatic ring, and it begins from intermediate 1, ends in intermediate 3 via TS3. The result of attack is the bonding of $\mathrm{C} 2-\mathrm{O}_{\mathrm{d}}$, and the alkylperoxo species (intermediate 3 ) is formed as follow. The distance of $\mathrm{C} 2$ and $\mathrm{O}_{\mathrm{p}}$ is decreased (from 3.16 $\AA$ to $1.45 \AA$ 证 $1.81 \AA$ in triplet state, from $3.27 \AA$ to $1.49 \AA$ via $1.76 \AA$ in quintet state, as shown in Fig. 5, and from $3.27 \AA$ to $1.48 \AA$ via $1.77 \AA$ in septet state) along with one electron transfer from substrate to superoxo. Seeing from the potential energy profiles in Fig. $6,{ }^{5} \mathbf{T S} 3$ is the lowest-lying transition state for superoxo attack among all three spin states. But the septet state is the ground state of reactive species. This process is also a TSR scenario, in which the initially excited quintet states, crossover through the high-spin ground septet states to promote superoxo attack. The effective activation barrier is $22.6 \mathrm{kcal} \mathrm{mol}^{-1}$ (shown in Fig. 6).

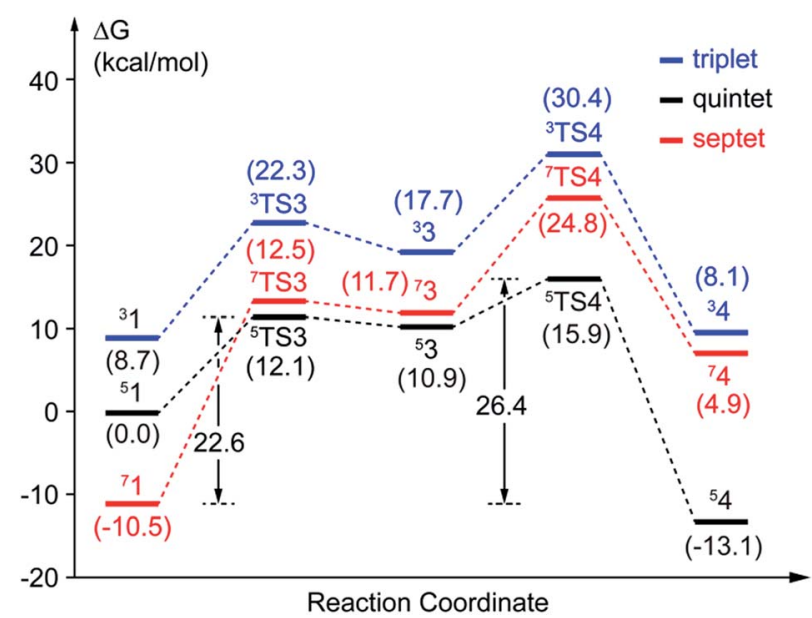

Fig. 6 Potential energy profiles of pathway $B$. The values with parentheses are relative free energies.

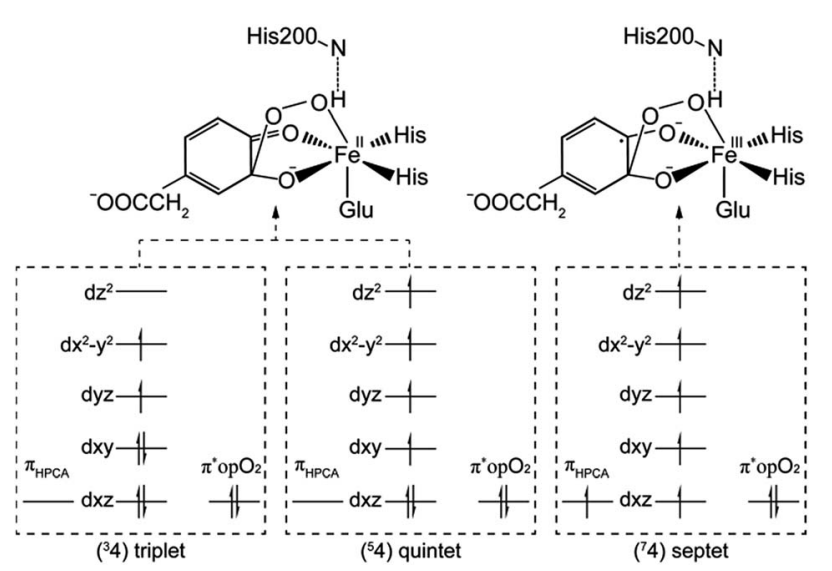

Fig. 7 The electron configurations of alkyl(hydro)peroxo for triplet state, quintet state and septet state.

(b) Proton transfer. The proton transfer occurs between $\mathrm{O} 1$ and $\mathrm{O}_{\mathrm{p}}$. There are two different type of reaction mechanism: one is a proton-coupled electron transfer (PCET) process with one net electron flows toward Fe in triplet and quintet states; and the other is a proton transfer procedure without electron migration in septet state. This reaction step also results in producing three kinds of electron characteristic of alkyl(hydro) peroxo species (Fig. 7). The relative free energy barrier is $12.7 \mathrm{kcal} \mathrm{mol}^{-1}$ in triplet state, $5.0 \mathrm{kcal} \mathrm{mol}^{-1}$ in quintet state, and $13.1 \mathrm{kcal} \mathrm{mol}^{-1}$ in septet state, respectively (shown in Fig. 6). However, the relative energy of TS4 is much higher than TS3. The reaction rate of the pathway $B$ is affected by both superoxo attack and proton transfer.

Additionally, oxo attack can also probably occur between distal oxygen and C1 of HPCA. But this possibility has been ruled out on the basis of a recent research. ${ }^{31}$

\subsection{The favorable reaction pathway}

In comparison with the total effective activation barrier of the two pathways, we find that the pathway $\mathrm{A}\left(\Delta G_{\mathrm{teff}}^{\ddagger}\right.$ is $\left.22.9 \mathrm{kcal} \mathrm{mol}^{-1}\right)$ is more favorable than pathway B $\left(\Delta G_{\text {teff }}^{ \pm}\right.$is $26.2 \mathrm{kcal} \mathrm{mol}^{-1}$ ). Additionally, we also do some research on the pathway of proton transfer via His200, which is mentioned in previous studies. It is regrettable that we have not located a transition state for this proton-transfer process, and no stable intermediate structure for protonation of His200 is found. Instead, a PES scan of proton transfer from substrate to His200 is carried out by changing the distance of $\mathrm{O} 1$ and $\mathrm{H} 1$ in $0.1 \AA$ increments. Meantime, the intrinsic reaction coordinate (IRC) connecting 1, TS1, and 2 is generated by the same abscissa as the distance of $\mathrm{O} 1$ and $\mathrm{H} 1$. The results are shown in Fig. 8, the relative energy of proton transfer from substrate to His200 is monotone increasing along with the increase of the $r(\mathrm{O} 1-\mathrm{H} 1)$, and the estimated value of relative energy barrier is no less than $30 \mathrm{kcal} \mathrm{mol}^{-1}$. On the contrary, the relative energy barrier of 1TS1-2 is no more than $25 \mathrm{kcal} \mathrm{mol}^{-1}$. Thus, proton transfer from substrate to proximal oxygen is more favorable than to His200. In summary, pathway A is both thermodynamically and kinetically more favorable than the others. 


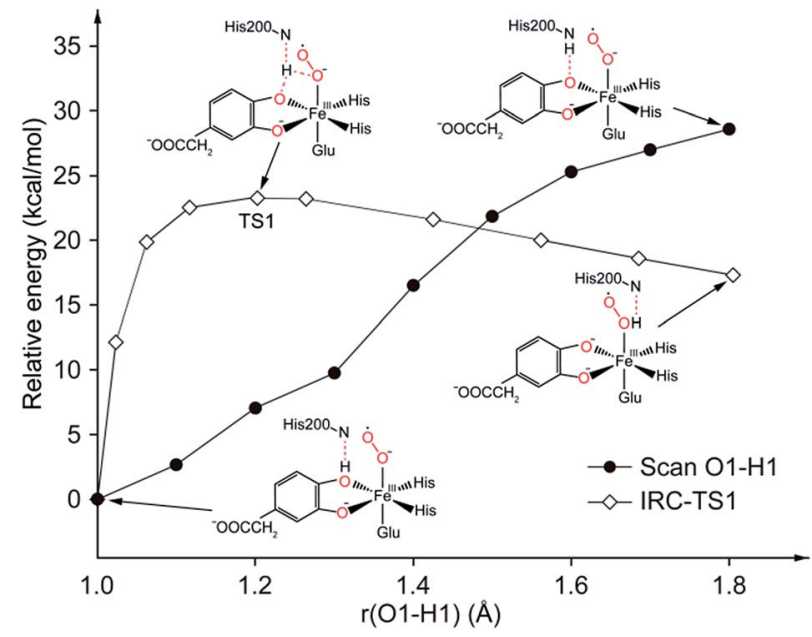

Fig. 8 PES scan of proton transfer from substrate to His200 and IRC connecting 1, TS1, and 2. All calculations are performed at ONIOM (B3LYP/6-31G(d):Amber) level in quintet state.

\section{Conclusions}

The two parallel pathways to form consensus alkyl(hydro)peroxo species are shown in this study. Pathway A can be described as proton transfer from monoanionic catechol substrate to proximal oxygen of dioxygen with subsequently distal oxygen of hydroperoxo attacks on the aromatic ring. Pathway B is performed by the attack of distal oxygen and followed with a PCET procedure. From the different potential energy profiles of three spin states, we can draw the conclusion that the triplet state is no catalytically relevance for the much higher energy profile than the others. Meanwhile, the quintet is the ground state for the whole process except intermediate 1 . The first step of the two pathways is a TSR scenario.

His200 is found not to work as a proton carrier, but to provide a weak interaction with the proton to stabilize the active center. The proton transfer takes place between the catecholic substrates and superoxide anion directly. By comparing the pathway A, pathway B, and proton-transfer process via His200 from the viewpoint of chemical thermodynamics and kinetics, the pathway A is the most favorable one of the three.

\section{Conflicts of interest}

There are no conflicts to declare.

\section{Acknowledgements}

This work was supported by National Natural Science Foundation of China (No. 21476091), Natural Science Foundation of Guangdong province, China (No. 2015-A030313801), Natural Science Foundation for Young Talent Project of Guangdong, China. We thank Richard Chang and Ziang Li for technical assistance.

\section{Notes and references}

1 G. Lin, G. Reid and T. D. H. Bugg, Chem. Commun., 2000, 1119-1120.

2 F. H. Vaillancourt, J. T. Bolin and L. D. Eltis, Crit. Rev. Biochem. Mol. Biol., 2006, 41, 241-267.

3 E. G. Kovaleva and J. D. Lipscomb, Nat. Chem. Biol., 2008, 4, 186-193.

4 T. D. H. Bugg, in Iron-Containing Enzymes: Versatile Catalysts of Hydroxylation Reactions in Nature, The Royal Society of Chemistry, 2011, pp. 42-66.

5 M. D. White and E. Flashman, Curr. Opin. Chem. Biol., 2016, 31, 126-135.

6 K. D. Koehntop, J. P. Emerson and L. Que, JBIC, J. Biol. Inorg. Chem., 2005, 10, 87-93.

7 P. C. A. Bruijnincx, G. van Koten and R. J. M. Klein Gebbink, Chem. Soc. Rev., 2008, 37, 2716-2744.

8 E. G. Kovaleva, M. B. Neibergall, S. Chakrabarty and J. D. Lipscomb, Acc. Chem. Res., 2007, 40, 475-483.

9 M. M. Mbughuni, M. Chakrabarti, J. A. Hayden, K. K. Meier, J. J. Dalluge, M. P. Hendrich, E. Münck and J. D. Lipscomb, Biochemistry, 2011, 50, 10262-10274.

10 K. L. Henderson, V. H. Le, E. A. Lewis and J. P. Emerson, JBIC, J. Biol. Inorg. Chem., 2012, 17, 991-994.

11 S. L. Groce and J. D. Lipscomb, J. Am. Chem. Soc., 2003, 125, 11780-11781.

12 M. W. Vetting, L. P. Wackett, L. Que, J. D. Lipscomb and D. H. Ohlendorf, J. Bacteriol., 2004, 186, 1945-1958.

13 F. H. Vaillancourt, G. Labbé, N. M. Drouin, P. D. Fortin and L. D. Eltis, J. Biol. Chem., 2002, 277, 2019-2027.

14 M. Sylvestre, T. Macek and M. Mackova, Curr. Opin. Biotechnol., 2009, 20, 242-247.

15 S. Dai, F. H. Vaillancourt, H. Maaroufi, N. M. Drouin, D. B. Neau, V. Snieckus, J. T. Bolin and L. D. Eltis, Nat. Struct. Biol., 2002, 9, 934-939.

16 E. G. Kovaleva and J. D. Lipscomb, Science, 2007, 316, 453457.

17 J. D. Lipscomb, Curr. Opin. Struct. Biol., 2008, 18, 644-649.

18 E. G. Kovaleva and J. D. Lipscomb, Biochemistry, 2008, 47, 11168-11170.

19 H. J. Cho, K. Kim, S. Y. Sohn, H. Y. Cho, K. J. Kim, M. H. Kim, D. Kim, E. Kim and B. S. Kang, J. Biol. Chem., 2010, 285, 34643-34652.

20 S. Chatterjee, D. Sheet and T. K. Paine, Chem. Commun., 2013, 49, 10251-10253.

21 F. H. Vaillancourt, S. Han, P. D. Fortin, J. T. Bolin and L. D. Eltis, J. Biol. Chem., 1998, 273, 34887-34895.

22 F. H. Vaillancourt, C. J. Barbosa, T. G. Spiro, J. T. Bolin, M. W. Blades, R. F. B. Turner and L. D. Eltis, J. Am. Chem. Soc., 2002, 124, 2485-2496.

23 D. M. Arciero and J. D. Lipscomb, J. Biol. Chem., 1986, 261, 2170-2178.

24 E. G. Kovaleva and J. D. Lipscomb, Biochemistry, 2012, 51, 8755-8763.

25 S. L. Groce and J. D. Lipscomb, Biochemistry, 2005, 44, 71757188. 
26 J. P. Emerson, E. G. Kovaleva, E. R. Farquhar, J. D. Lipscomb and L. Que, Proc. Natl. Acad. Sci., 2008, 105, 7347-7352.

27 M. M. Mbughuni, M. Chakrabarti, J. A. Hayden, E. L. Bominaar, M. P. Hendrich, E. Münck and J. D. Lipscomb, Proc. Natl. Acad. Sci., 2010, 107, 16788-16793.

28 G. J. Christian, S. Ye and F. Neese, Chem. Sci., 2011, 3, 16001611.

29 G. Dong, S. Shaik and W. Lai, Chem. Sci., 2013, 4, 3624-3635.

30 G. Dong and W. Lai, J. Phys. Chem. B, 2014, 118, 1791-1798.

31 G. J. Christian, F. Neese and S. Ye, Inorg. Chem., 2016, 55, 3853-3864.

32 E. G. Kovaleva, M. S. Rogers and J. D. Lipscomb, Biochemistry, 2015, 54, 5329-5339.

33 D. A. Case, J. T. Berryman, R. M. Betz, D. S. Cerutti, T. E. Cheatham III, T. A. Darden, R. E. Duke, T. J. Giese, H. Gohlke, A. W. Goetz, N. Homeyer, S. Izadi, P. Janowski, J. Kaus, A. Kovalenko, T. S. Lee, S. LeGrand, P. Li, T. Luchko, R. Luo, B. Madej, K. M. Merz, G. Monard, P. Needham, H. Nguyen, H. T. Nguyen, I. Omelyan, A. Onufriev, D. R. Roe, A. Roitberg, R. Salomon-Ferrer, C. L. Simmerling, W. Smith, J. Swails, R. C. Walker, J. Wang, R. M. Wolf, X. Wu, D. M. York and P. A. Kollman, AMBER 2015, University of California, San Francisco, 2015.

34 J. C. Gordon, J. B. Myers, T. Folta, V. Shoja, L. S. Heath and A. Onufriev, Nucleic Acids Res., 2005, 33, W368-W371.

35 R. Anandakrishnan, B. Aguilar and A. V. Onufriev, Nucleic Acids Res., 2012, 40, W537-W541.

36 P. Campomanes, U. Rothlisberger, M. Alfonso-Prieto and C. Rovira, J. Am. Chem. Soc., 2015, 137, 11170-11178.

37 K. G. Sprenger, V. W. Jaeger and J. Pfaendtner, J. Phys. Chem. $B, 2015,119,5882-5895$.
38 T. Darden, D. York and L. Pedersen, J. Chem. Phys., 1993, 98, 10089-10092.

39 M. J. Frisch, G. W. Trucks, H. B. Schlegel, G. E. Scuseria, M. A. Robb, J. R. Cheeseman, G. Scalmani, V. Barone, B. Mennucci, G. A. Petersson, H. Nakatsuji, M. Caricato, X. Li, H. P. Hratchian, A. F. Izmaylov, J. Bloino, G. Zheng, J. L. Sonnenberg, M. Hada, M. Ehara, K. Toyota, R. Fukuda, J. Hasegawa, M. Ishida, T. Nakajima, Y. Honda, O. Kitao, H. Nakai, T. Vreven, J. A. Montgomery Jr, J. E. Peralta, F. Ogliaro, M. Bearpark, J. J. Heyd, E. Brothers, K. N. Kudin, V. N. Staroverov, R. Kobayashi, J. Normand, K. Raghavachari, A. Rendell, J. C. Burant, S. S. Iyengar, J. Tomasi, M. Cossi, N. Rega, J. M. Millam, M. Klene, J. E. Knox, J. B. Cross, V. Bakken, C. Adamo, J. Jaramillo, R. Gomperts, R. E. Stratmann, O. Yazyev, A. J. Austin, R. Cammi, C. Pomelli, J. W. Ochterski, R. L. Martin, K. Morokuma, V. G. Zakrzewski, G. A. Voth, P. Salvador, J. J. Dannenberg, S. Dapprich, A. D. Daniels, Ö. Farkas,J. B. Foresman, J. V. Ortiz, J. Cioslowski and D. J. Fox, Gaussian, Inc., Wallingford, CT, 2009.

40 T. Vreven, K. S. Byun, I. Komáromi, S. Dapprich, J. A. Montgomery, K. Morokuma and M. J. Frisch, J. Chem. Theory Comput., 2006, 2, 815-826.

41 J. Wang, P. Cieplak and P. A. Kollman, J. Comput. Chem., 2000, 21, 1049-1074.

42 A. Marquez and J. Fernandez Sanz, J. Am. Chem. Soc., 1992, 114, 10019-10024.

43 S. Ye and F. Neese, Proc. Natl. Acad. Sci., 2011, 108, 12281233.

44 T. Lu and F. Chen, J. Comput. Chem., 2012, 33, 580-592. 